\title{
POR UM REALISMo NÃo NATURALISTa
}

Markus Gabriel ${ }^{1}$

(Rheinische Friedrich-Wilhelms-Universität Bonn)

Mesmo onde existem dúvidas legítimas relativamente à sua aplicabilidade, parece que é frequente saber o que significa o Naturalismo e aquilo a que se vincula. Numa análise mais precisa é, no entanto, manifesto que o naturalismo tem uma posição bastante indeterminada. Apresenta-se até como uma estratificação de teses logicamente independentes umas das outras mais do que como uma posição susceptível de teorização.

Podem distinguir-se pelo menos três teses que se assumem como naturalistas: uma tese metafísica e duas teses de continuidade ${ }^{2}$. Quando se começa a pensar em Naturalismo desemboca-se na tese metafísica de que não existe nada de sobrenatural, mas apenas o que é natural. Neste nível muito geral o "naturalismo" contrasta com o "supranaturalismo". Como esta tese se torna rapidamente numa confissão anti-religiosa e com frequência teologicamente desinformada - devido ao facto de a sua história anterior ao século XVIII e início do século XIX não ser muitas vezes incorporada na reflexão -, ou se torna numa fórmula vazia de declaração de respeito pela cientificidade das ciências naturais, ela não chega a ser na actualidade mais do que a mera afirmação de que no mundo tudo se passaria como deveria ser. Exprime-se, designadamente com isto, que não existem gnomos nem fantasmas, englobando de um só fôlego Deus, a alma, o eu, valores morais,

$\overline{1}$ gabrielm@uni bonn.de

${ }^{2}$ Sobre a classificação e discussão acerca de possíveis conceitos de naturalismo, vejase: Susan Haack, "Naturalism Disambiguated", in: Id., Evidence and Inquiry, Oxford: Blackwell, 1993, pp. 118-138; Geert Keil, "Naturalismus", in Id. - H. Schnädelbach (eds.), Naturalismus, Frankfurt a. Main: Suhrkamp, 2000, pp. 7-45.

Philosophica, 48, Lisboa, 2016, pp. 9-30. 
ou até mesmo estados mentais na categoria dos fantasmas sobrenaturais. Só o mundo deve existir realmente e este seria um "big physical object", como escreve David Lewis logo no início do seu livro On the Plurality of Worlds ${ }^{3}$.

Por outro lado, pensa-se também no "naturalismo" enquanto duas teses de continuidade. A primeira tese de continuidade afirma que qualquer forma de ciência - e também a lógica, a matemática e a filosofia - apenas poderá ser uma continuação das melhores ciências naturais. É aproximadamente isso que Willard van Orman Quine sugere quando pretende, por exemplo, "naturalizar" a epistemologia e se entende a si mesmo como naturalista ${ }^{4}$.

A segunda tese de continuidade pertence mais à área da biologia e da antropologia. Ela sustenta que o homem pertence ao reino dos animais. $\mathrm{Na}$ sua versão mais radical chega até ao ponto de defender que se compreende inteiramente o homem quando se investigam as suas capacidades mais louvadas - linguagem, pensamento, intencionalidade, razão e moral - no âmbito da psicologia evolucionista, a fim de estabelecer uma continuidade entre o homem e o restante reino dos animais ${ }^{5}$. Poder-se-ia descascar muitas outras teses que foram subsumidas sob a rubrica do "naturalismo". Decisivo para o que se segue é que existe uma pluralidade de teses logicamente independentes umas das outras que são designadas como "naturalismo".

Ao híbrido de que me ocupo hoje chamo naturalismo de uso comercial. Neste, encontra-se uma amálgama de teses logicamente independentes entre si. À primeira vista não existe razão para presumir que se deva defender sempre em conjunto o naturalismo 1 até ao naturalismo 3. Avançando esta objecção contra o naturalismo, obtêm-se regularmente respostas que conduzem a uma unificação homogeneizante das três teses mencionadas do naturalismo. Introduzamos uma tese unificante que designarei, em alusão ao famoso brinquedo "Lego", por legocentrismo ${ }^{6}$. O legocentrismo diz

3 David Lewis, On the Plurality of Worlds, Malden/MA., 1986, p. 1.

4 Willard van Orman Quine, "Epistemology Naturalized", in: Idem., Ontological Relativity and Other Essays, New York, 1969, pp. 69-90.

5 Cf. neste contexto os contributos in: Ludger Honnefelder/Matthias C. Schmidt (eds.), Naturalismus als Paradigma. Wie weit reicht die naturwissenschaftliche Erklärung des Menschen?, Berlin, 2007.

6 Tese sustentada, por exemplo, em Max Tegmark, Our mathematical Universe. My Quest for the Ultimate Nature of Reality, New York, 2014, pp. 235-272, sobretudo na página 271: "Everything, even light and people, seems to be made of particles." Neste caso Tegmark acrescenta: "These particles are purely mathematical objects in the sense that their only intrinsic properties are mathematical properties - numbers with names like charge, spin and lepton numbers." Aqui parece haver, a par do legocentrismo já problemático, um equívoco entre objectos que apenas podemos descrever matematicamente e objectos matemáticos. 
que tudo o que existe é formado por partículas elementares, cujo comportamento se pode, no melhor dos casos, descrever fisicamente. O mesmo seria válido para os genes e as suas mutações e, consequentemente, para os conceitos fundamentais da teoria da evolução. Visto que o homem pertence como ser vivo ao reino dos animais, poderá então reconstruir-se todo o comportamento humano com o auxílio de uma caixa de construções da Lego. Tal não conseguimos, porém, porque teríamos de processar demasiados dados. O legocentrismo considera o mundo demasiado complexo para ser perscrutado na sua totalidade, embora, no mesmo fôlego, presuma saber como ele funciona, e até mais, como nós humanos funcionamos propriamente enquanto mecanismos relojoeiros altamente complexos ou, a meu ver, enquanto computadores quânticos. Aqui se confundem todas as teses naturalistas imagináveis. A unificação grosseira é obtida à custa da mescla das três teses naturalistas logicamente independentes entre si.

No naturalismo de uso comercial, que aspiraria a ser naturalista em todos os domínios e em todas as formas de representação, trata-se de uma imagem do mundo bastante difusa. Ainda que o naturalismo de uso comercial, enquanto imagem do mundo bastante difusa, possua traços mais ideológicos do que científicos, ele merece uma abordagem filosófica. Uma das tarefas principais da filosofia é a crítica ideológica. Se o naturalismo de uso comercial, devido à sua confusa quantidade de premissas, é menos apropriado para dar informação racional sobre si mesmo, será uma tarefa da filosofia observar um cerne racional e demonstrar o manuseamento errado da agulha que o naturalismo de uso comercial efectua.

Proponho, por isso, analisar seguidamente em pormenor alguns dos manuseamentos errados da agulha e as lacunas argumentativas que subjazem ao naturalismo de uso comercial. Ao fazê-lo, não sigo um fim meramente destrutivo, pois trata-se para mim, também, de pôr no lugar do naturalismo de uso comercial um realismo muito geral, que designei como um realismo neutral ${ }^{7}$. O realismo neutral diz finalmente que Up Quarks, mãos, a República Federal da Alemanha, o passado, as personagens e acontecimentos em Fausto. Da Tragédia Primeira Parte e factos morais pertencem a áreas objectuais em que conseguimos ter conviç̧ões seguras da sua verdade. Up Quarks ou quasares não têm mais direito a existir do que os nossos pensamentos sobre eles, eles não são, por assim dizer, melhores no existir e também não são mais apropriados para determinar se os nossos pensamentos acerca deles são verdadeiros ou errados enquanto

7 Markus Gabriel, “Neutraler Realismus”, Philosophisches Jahrbuch 121 (II/2014), 352-372. 
factos estéticos ou morais. Não existe um declive ontológico (a respeito da existência), por exemplo, entre factos físicos e morais, de maneira que os primeiros devam ser acoplados aos últimos para formular afirmações morais consistentes de verdade.

Na primeira parte do meu contributo investigarei um problema epistemológico central do naturalismo. Este problema designo-o como andar à pendura. O naturalismo salta para cima do comboio racional do realismo e onera-o com suposições suplementares infundadas e dispensáveis.

$\mathrm{Na}$ segunda parte do meu contributo argumento que o naturalismo também não se pode refugiar na metafísica, porque aí repete-se o problema do andar à pendura sob sinais modificados. Aqui discutirei em especial o problema do mundo, que se coloca quando se pensa que existir significa pertencer ao mundo, estar presente no mundo, ou acontecer-se no mundo.

$\mathrm{Na}$ terceira e última parte esboçarei, pelo contrário, a minha alternativa, que denomino "ontologia de campos de sentido" (Sinnfeldontologie). Não a poderei defender na sua totalidade, porque isso ultrapassaria de longe o âmbito de um ensaio ${ }^{8}$. Concentro-me, ao invés, em duas linhas principais e antinaturalistas desta ontologia: o pluralismo ontológico e o realismo ontológico.

\section{Andar à pendura. Do realismo até ao naturalismo, e de volta}

Poderia opinar-se que o debate sobre o realismo se ocupa com a questão de saber se o mundo ou a realidade é independente das nossas opiniões. Com tal opinião não se estaria pelo menos numa posição solitária, embora a meu ver se estivesse numa posição perdida. Chamemos a isto a concepção padrão da metafísica, a que retornarei em breve. Numa versão ainda mais tradicional, que foi rejeitada sucessivamente e com sucesso por Kant, Fichte, Schelling, Hegel, Nietzsche, Heidegger e Carnap, ser-se-ia então realista ao considerar que existem coisas independentes da consciência, que constituem uma área total: o mundo exterior. Em contraste com a concepção padrão da metafísica podemos designar este realismo como realismo ingénuo. O realismo ingénuo não é ingénuo pelo facto de o idealismo subjectivo, o subjectivismo ou o fenomenalismo que se the opõem, serem menos ingénuos e mais bem fundamentados. Ele é, pelo contrário, problemático, porque, numa certa leitura, está convencido de

8 Cf. o extenso tratamento em Markus Gabriel, Sinn und Existenz. Eine realistische Ontologie, Berlin: Suhrkamp, 2016. 
que diz algo verdadeiro, enquanto, numa outra leitura, não é claro se diz efectivamente alguma coisa.

Evidentemente, existe um mundo exterior independente da consciência num qualquer sentido trivial da palavra. Se me virar e não percepcionar mais o meu ecrã, ele ainda permanece lá. Isto provavelmente nunca ninguém contestou, nem o muito fustigado e, por isso, já quase não lido, George Berkeley, que talvez modestamente achava que todos os conteúdos da consciência nada mais seriam do que os conteúdos da consciência de alguém. Como a seu ver existe mais do que uma consciência, mais do que um espírito - pelo menos Deus e todos os leitores e leitoras desta frase -, o mundo não desaparece se fecho os olhos ou se me abismo num sono inconsciente e profundo. Também de acordo com Berkeley o mundo exterior não é dependente da minha consciência. Quando muito ele sustenta uma tese sobre a estrutura e a composição da realidade, que afirma nada existir que não seja ou espírito ou o conteúdo de um espírito, para o que aduz sobretudo argumentos epistemológicos.

Num outro sentido, mostra-se erróneo resumir tudo o que é independente da consciência na categoria dos objectos que pertencem ao mundo exterior, porque o conceito de "mundo exterior" é desesperadamente indefinido. Se alguma coisa pertence ao mundo exterior exactamente no momento em que é, como é, quer eu queira isso quer não, então há demasiadas coisas que pertencem ao mundo exterior ${ }^{9}$. Eu, por exemplo, nasci como cidadão alemão, quer queira quer não. Este estatuto normativo implica muitos deveres e direitos, dos quais não estou ciente. Eles são independentes da minha consciência. Embora os meus deveres e direitos não se encontrem "lá fora", quer dizer que o meu estatuto normativo como cidadão alemão existe até agora despercebido por mim fora do meu crânio ou numa distância considerável da minha consciência. Obviamente, poder-se-ia objectar neste ponto que direitos e deveres de cidadãos dependem, num qualquer sentido, da consciência, pelo menos no sentido de que nunca existiriam se nunca tivesse existido a consciência. Assim, como se sabe, John Searle sustenta a tese de que funções normativas de estatuto e, em geral, factos sociais existem apenas enquanto forem construídos, isto é, quando mantemos determinadas atitudes de "reconhecimento" para com eles, e que por isso eles são antes de mais produzidos ${ }^{10}$. No entanto,

9 Esta é uma das fraquezas principais da noção do realismo de Maurizio Ferraris. Cf., por exemplo, o seu Documentality. Why It Is Necessary to Leave Traces, New York: Fordham University Press, 2009; Idem, "Transcendental Realism", The Monist 98:2 (2015), 215-232.

10 John Searle, Making the Social World. The Structure of Human Civilization. New York: 
também Searle continua a dever uma resposta à questão de saber em que medida isto tem alguma coisa a ver com a dependência da consciência. Em todo o caso, desta tese não se infere que alguma coisa existe unicamente se existir consciência. Também nunca existiriam unhas humanas, se nunca existisse consciência, do que até agora ninguém deduziu a consequência de que as unhas são dependentes da consciência. Consequentemente, o sentido geral convencionado de "dependência da consciência" não se pode esgotar no descobrir daquilo que existe apenas se existir consciência. O sentido convencionado deve ser de qualquer modo mais rigoroso.

Talvez assim se pudesse acrescentar aqui que o recurso a Berkeley, pelo menos no que em geral se relaciona com o seu idealismo, nos ajudará a compreender o que significa que algo possa ser dependente da consciência. Não diz Berkeley que todos os objectos com os quais nos relacionamos como se fossem independentes da nossa consciência são conteúdos da consciência de outrem? Neste caso, a tese seria que apenas há conteúdos de consciência e consciências. Mas também neste cenário é pouco claro o que propriamente significa que conteúdos de consciência estejam dependentes da consciência. Suponhamos, por exemplo, que acho que estou a ver uma cadeira. Mas então, de acordo com esta concepção, engano-me em que esteja aí à frente uma cadeira. Tenho, pelo contrário, apenas uma impressão que não compreendo inteiramente, de modo que tomo a impressão de uma cadeira ou uma série de impressões de uma cadeira por uma cadeira. Também se pode argumentar ainda a favor da tese aparentemente plausível de que impressões - como, por exemplo, dores - são dependentes da consciência e então ter-se-ia aparentemente uma concepção autêntica da dependência da consciência, contra a qual se poderia perfilar um respectivo contra-argumento da independência da consciência. Mas de onde vem realmente o conteúdo da impressão? Como explica Berkeley que tenho a impressão de uma cadeira e não a impressão de um sapo? Provavelmente com recurso a "Deus, [...] a valeta"11, como escreveu Hegel desdenhosamente neste contexto. Já que Berkeley nem sequer consegue explicar a aparência de objectividade, Deus é introduzido como figurante ou justamente como valeta para "explicar" porque aparece perante mim uma cadeira e não um sapo. Talvez seja possível supor aqui, com Leibniz, que o material mental para cadeiras surge do interior da minha mónada e que eu não perscruto in ipso actu operandi este surgir. Mas também neste ponto Leibniz cai na difi-

Oxford University Press, 2010.

11 Georg Wilhelm Friedrich Hegel, Vorlesungen über die Geschichte der Philosophie, Frankfurt/M.: Suhrkamp, 1979, p. 273. 
culdade não negligenciável de tornar compreensível uma comunicação das mónadas, de modo que também ele precisa de recorrer a "Deus, a valeta", de que por sua vez se queixou Hegel ${ }^{12}$.

Mesmo que fosse possível resolver todos estes problemas, não se teria obtido qualquer conceito relevante sobre a dependência da consciência que ainda fosse de todo compatível com o facto de poder considerar-se algo como dependente da consciência e outro algo como independente da consciência. Pelo contrário, constituiu-se um conceito de "consciência" que jamais permite compreender como é que alguma vez foi possível ter considerado algo como independente da consciência. Em Berkeley, Leibniz e nas suas actualizações analíticas, como por exemplo nos posteriores Michael Dummett e John Foster, tudo é por fim demasiado dependente da consciência, de modo que de repente não se compreende mais o que é a independência da consciência e, por isso, inclinamo-nos a negar que haja ainda algo que possa ser independente da consciência ${ }^{13}$.

Neste ponto uma outra derradeira tentativa de resgate da concepção do Realismo ingénuo supõe que algo é unicamente dependente de consciência, se apenas existir porque existe consciência. Mas então, os artefactos serão dependentes da consciência. No entanto, cadeiras, catedrais, sondas espaciais pertencem ao mundo exterior em qualquer sentido aceitável da palavra. E se fosse comprovado que os marcianos construíram, em tempos imemoriáveis, a lua da Terra? Ela será então dependente da consciência? Ou se fosse verdade que Deus, como pensam os criacionistas fundamentalistas dos Estados Unidos, tenha criado o universo? Seria tudo dependente da consciência, na medida em que atribuímos consciência a Deus?

12 Veja-se o juízo fulminante de Hegel, Ibid., p. 255: "Por isso, Deus tem um papel muito maior na filosofia mais recente do que na antiga. Na mais recente, o conceber (das Begreifen) é a exigência principal, que domina o antagonismo absoluto dominante, pensar e ser. Até onde os pensamentos progridem, tão vasto o universo; onde o conceber finda, termina o universo e começa Deus; é assim que até se pensa que, no conceber, Deus é rebaixado até à finitude. - Começa-se pelo determinado: isto e aquilo é necessário, mas não concebemos a unidade destes momentos; esta cai, pois, em Deus. Deus é por assim dizer a valeta onde confluem todas estas contradições. Tal colectânea popular é a Teodiceia de Leibniz. Aí há sempre muitas ocasiões para inventar desculpas: na contradição entre justiça e a bondade, que uma temperará a outra; como a presciência de Deus concorda com a liberdade humana; - muitas sínteses, que nem chegam ao fundamento, nem apresentam ambos os lados como momentos.

13 Cf. John Foster, The Case for Idealism, London: Routledge \& Kegan Paul, 1982; Idem, A World for Us. The Case for Phenomenalistic Idealism, Oxford: Oxford University Press, 2008; Michael Dummett, Thought and Reality, New York: Oxford University Press, 2008. 
A indefinição do conceito de "dependência da consciência" projecta luz sobre o conceito contrastante de independência de consciência. Quando se verifica que temos apenas uma noção muito vaga sobre algo reconhecido, como "dependente da consciência", o mesmo também é válido ipso facto para o conceito contrastante.

O problema do realismo ingénuo existe, ou porque ele é trivial e não é impugnado por ninguém, ou porque é indefinido, pois recorre a um conceito vago de "mundo exterior" que, sob um olhar mais cuidadoso, se evapora numa mera impressão da realidade bruta de qualquer objecto. Filosoficamente nada se pode fazer com isto. $\mathrm{O}$ realismo ingénuo assim compreendido é um gesto vazio e incapaz de teoria.

Então podemos começar pelo ponto que já tocámos: pela concepção padrão da metafísica, porque esta não necessita no primeiro arranque do conceito da consciência e da distinção precária entre objectos dentro e objectos fora da consciência. A concepção padrão da metafísica diz então que o mundo ou a realidade será independente das nossas opiniões.

No entanto, aqui volta de imediato a pôr-se a questão de saber porque alguém sustentaria tal coisa. Porque a concepção padrão da metafísica é num certo sentido trivial e, num outro sentido, provavelmente pouco clara. Por isso, é preferível antecipar a seguinte ponderação ao debate sobre o realismo: muitas das nossas afirmações são verdadeiras, porque os factos cuja existência as sustentam existem. Muitos dos factos existentes teriam além disso também existido, mesmo que nunca alguém tivesse formado uma opinião a seu respeito. Designamos estes factos como factos maximamente modais e robustos ${ }^{14}$. Quer-se ser realista, porque existem factos maximamente modais e robustos. O realismo é o nome geral pelo qual se demonstra respeito pelos factos maximamente modais e robustos. Esta tese geral, de que existem factos maximamente modais e robustos que, pelo menos, não pertencem necessariamente a um campo objectual privilegiado, poder-se-á caracterizar como a tese fundamental do realismo neutral. Considero cum grano salis esta tese fundamental como inocente e irei reatá-la na parte construtiva do meu contributo, porque também defendo um realismo neutral. Este aliás não privilegia os factos maximamente modais e robustos perante os factos que apenas existem se nós existirmos ou se nos apercebermos de que eles existem.

O naturalismo de uso comercial não se detém neste ponto nem onera a tese fundamental do realismo neutral com suposições adicionais

14 Cf. neste contexto Markus Gabriel, "Existenz, realistisch gedacht”, in: Idem (ed.), Der Neue Realismus, Berlin: Suhrkamp, 2014, pp. 171-199. 
que, passo a passo, se unem no seu enquadramento de premissas. O próximo acerto de agulhas neste lugar será por isso efectuado de modo que não nos contentemos mais com os factos maximamente modais e robustos em geral, senão que se presuma que podemos reconhecê-los numa determinada atitude privilegiada. Esta atitude privilegiada foi designada por Bernard Williams como "o projecto de uma investigação pura" ${ }^{15}$. Este projecto tenciona estabelecer um catálogo sistematicamente coerente dos factos maximamente modais e robustos. Neste caso, ou somos mais ou menos bem-sucedidos, ou provavelmente falhamos por completo na determinação dos factos maximamente modais e robustos. Williams e, incentivado por ele, Adrian W. Moore designam esta imagem como "a concepção absoluta da realidade (the absolute conception of reality)" $"$.

No seu livro Points of View, Moore designa-a mesmo como a "basic assumption" e presume que apenas esta torna compreensível que representações sejam "representações daquilo que existe de qualquer forma (representation are representation of what is there anyway)"17. Ele até dá mais um passo em frente e vincula esta consideração ao conceito de verdade, de modo que daí resulta a seguinte imagem global ou do mundo:

The truth of any true representation is determined by how the world is - by how reality is. There is only one world. This is what I mean when I talk about the unity of reality. ${ }^{18}$

Com isto Moore entregou-nos a forma lógica de uma imagem do mundo - que no passo seguinte se transforma no naturalismo de uso comercial -, na medida em que este considera a concepção absoluta da realidade como uma dádiva e explica com recurso à mesma por que motivo as ciências naturais desenvolvem teorias a que se pretende atribuir uma objectividade tanto quanto possível ilimitada. Seguindo o naturalismo comerciável, as ciências naturais elaboram o desenho daquela imagem do mundo que nos entrega a concepção absoluta da realidade de forma esquelética. Designo isto como "andar à pendura", porque a concepção epistemológica da objectividade é, em primeiro lugar, metafisicamente enriquecida (o que sobretudo Adrian W. Moore aceita) e, em seguida, instituída como explicação do sucesso epistémico das ciências naturais (o que tem para Moore uma importância apenas subordinada).

\footnotetext{
15 Bernard Williams, Descartes. The Project of Pure Enquiry, Sussex: Harvester Press, 1978.

16 Veja-se Adrian W. Moore, Points of View, Oxford: Oxford University Press, 1997.

17 Ibid., p. 227.

18 Ibid., p. 21.
} 
Deste modo, surge uma imagem do mundo que presume que o realismo se interessa, como também o naturalismo que lhe é acoplado, por aquilo que chamo o "mundo sem espectadores"19. Parece ser assim que, como realista, se tem preferência por um mundo sem espectadores. Negligencia-se assim facilmente, aliás, que o realismo neutral não está dependente de nenhuma imagem do mundo. Por isso, o naturalismo pode saltar para cima do realismo e confundi-lo discretamente com suposições adicionais. Chego assim à segunda parte do meu contributo, o problema do conceito do mundo.

\section{O problema do mundo}

O naturalismo de uso comercial poderia invocar que, pelo menos ele, oferece uma explicação metafísica bastante plausível da tese fundamental do realismo neutral. Ele poderia aceitar a objecção de andar epistemologicamente à pendura e apontar para o facto de que a sua posição é, na realidade, metafisicamente justificada. Que ele, apesar de tudo, deveria permanecer na corrida, se pudesse além disso justificar-se como explicação muito geral do sucesso pragmático das ciências naturais. Não poderá ser um milagre que a atitude objectivista que as ciências naturais reivindicam conduza ao progresso tecnológico e da medicina. Isto reside antes de mais no facto de as ciências naturais assumirem uma atitude metafísica privilegiada, porque nos põem em contacto com a camada fundamental da realidade dos verdadeiros factos maximamente modais e robustos, ou seja, com os factos naturais.

Mas esta via de pensamento tende antecipadamente para a sobre-generalização. A tese fundamental do realismo neutral é compatível com os demais factos naturais serem maximamente modais e robustos. Para cima deste comboio salta então o naturalismo e sustenta que existe exactamente uma camada fundamental da realidade, isto é: a realidade, e que as ciências naturais reconhecem a realidade.

Mas de onde sabemos, então, que os factos maximamente modais e robustos não são apenas uma qualquer quantidade de factos, mas, pelo contrário, um tapete uniforme de factos que constituem o mundo, a natureza, a realidade ou o universo? Por que deveriam desfrutar de um estatuto metafisicamente tão privilegiado que construímos uma imagem do mundo com base

19 Markus Gabriel, Porque não existe o Mundo, Lisboa: Temas e Debates, 2014, p. 14. 
neles, até mesmo a única moderna imagem do mundo, que se pode questionar apenas pelo preço da inimizade contra a ciência ou, pelo menos, da crítica da ciência? Quando se continua a perfurar aqui, deparamo-nos antes de mais com um medo e não com um argumento, o que Hilary Putnam descreveu recentemente - confessadamente caricaturando - de modo seguinte:

Today the most common use of the term, "naturalism" might be described as follows: philosophers - perhaps even a majority of all the philosophers writing about issues in metaphysics, epistemology, philosophy of mind, and philosophy of language - announce in one or another conspicuous place in their essays and books that they are "naturalists" or that the view or account being defended is a "naturalist" one. This announcement, in its placing and emphasis, resembles the placing of the announcement in articles written in Stalin's Soviet Union that a view was in agreement with Comrade Stalin's; as in the case of the latter announcement, it is supposed to be clear that any view that is not "naturalist" (not in agreement with Comrade Stalin's view) is anathema and could be possibly be correct. A further very common feature is that, as a rule, "naturalism" is not defined. ${ }^{20}$

Putnam aponta assim para o facto de que o naturalismo é aquela folha de figueira, sob a qual alguns filósofos contemporâneos escondem preferencialmente a sua metafísica. Assim a metafísica torna-se literalmente, às escondidas, numa meta-física, numa disciplina que, como apêndice vermiforme ainda temporariamente existente, elabora as perguntas não respondidas do conhecimento da natureza com o intuito de cuidar passo a passo de que não restará mais nenhuma pergunta genuinamente metafísica. A isto chama-se "naturalização" e o alvo será alcançado, se o mais importante tiver sido naturalizado: por exemplo, o livre arbítrio, a consciência, a verdade, o significado linguístico e a moral.

A imagem metafísica do mundo que dá o enquadramento de premissas para que as questões de naturalização se coloquem antes do mais nesta forma, não se pode deduzir das tecnociências e ciências naturais, nem se pode legitimar jamais como o específico conhecimento de uma ciência singular. O naturalismo não se deixa comprovar experimentalmente nem traduzir em afirmações que permitam previsões. Isto reside afinal no facto de que o naturalismo é, enquanto tese metafísica, extremamente geral e que ainda por cima quantifica num só movimento tudo o que existe.

Eventualmente não haveria nada a objectar contra isto, já que, de facto, se admite que precisamos num certo sentido de assumir alegações

${ }^{20}$ Hilary Putnam, Philosophy in an Age of Science. Physics, Mathematics and Skepticism, Cambridge/MA.: Harvard University Press, 2012, pp. 109-110. 
metafísicas. O problema específico, no entanto, é que estamos confrontados com uma metafísica inconfessada, que mascara mais ou menos habilmente as cargas de fundamentação que aceita. O naturalismo de uso comercial, por conseguinte, é assim bastante mal fundamentado. Apenas o primeiro passo, o passo da justificação muito geral de um realismo neutral pode alegar para si plausibilidade filosófica. A partir daí intromete-se no nosso caminho uma mundividência ${ }^{21}$, como Wittgenstein se pronunciou uma vez em Da Certeza.

O naturalismo de uso comercial nem é uma legítima disciplina científica nem sequer um enquadramento metodológico no qual as ciências naturais e as tecnociências operam ${ }^{22}$. Tanto como metafísica quanto como teoria das ciências ele paira entre o non sequitur e plausibilização indirecta por referência à autoridade da ciência, da modernidade, da técnica e do Iluminismo. Contudo, em meu entender, seria um erro querer-se substituir a imagem do mundo do naturalismo por uma outra imagem do mundo, porventura a imagem do mundo do idealismo ou do panpsiquismo, o que alguns anti-naturalistas têm em mente. Alguns defendem também uma imagem normativa do mundo, que aponta para o facto de que toda a prática epistemológica é orientada por normas constitutivas, que transcendem sempre cada conhecimento particular. $\mathrm{O}$ estatuto dos ditames das ciências naturais seria normativo e não descritivo, o que justificaria a sua extrema universalidade e já não comportaria nenhuma conclusão sobre um naturalismo metafísico. O ponto decisivo, contudo, é que não se precisa de uma imagem do mundo para se ser realista, isto é, para salvaguardar que as nossas conviçcões capazes de verdade sejam suficientemente objectivas para serem orientadas por uma norma genuína da verdade.

Aproximamo-nos novamente do problema do realismo, mas de outro modo. Para este efeito quero em primeiro lugar diferenciar entre metafísica e ontologia. Por metafisica entendo uma teoria da totalidade que é vinculada à persistente unidade de uma realidade universal do mundo. Evidentemente, pode-se entender por "metafísica" ainda outras teses: a tese de um contraste muito geral entre ser e aparência, ou a tese de que nem tudo o que existe pode ser descrito fisicamente (o que eu próprio defendo). No entanto, estas duas teses são tradicionalmente combinadas com a suposição de totalidade.

A ontologia, porém, ocupa-se da questão do que significa "existência", ou seja, segundo as preferências metodológicas, da questão do que é propriamente existência. A ontologia não precisa de supor que tudo que

${ }^{21}$ Ludwig Wittgenstein, Da Certeza, Lisboa: Edições 70, 1998, p. 119, \$422.

22 Cf. neste contexto também mais detalhado, Geert Keil, Kritik des Naturalismus, Berlin/ New York: de Gruyter, 1993. 
o existe está ligado entre si numa totalidade. Tal suposição de totalidade deve ser elaborada ontologicamente. Não é à primeira vista uma condição da ontologia que só exista alguma coisa enquanto pertencente a um todo universal, quando está de alguma forma subsumida em tudo o que existe.

Uma primeira imposição de uma ontologia bem-sucedida é que o seu conceito de existência não implique a priori, que muito ou até a maior parte daquilo que nós habitualmente alegamos que existe, na verdade ou na realidade, afinal não existe. Não é apenas através da inspecção do conceito de existência que sabemos o que existe e o que não existe. Elaboremos então uma lista muito incompleta do existente. Existe: a República Federal da Alemanha; exactamente um algarismo natural entre o 2 e o 4 , que é o 3; acontecimentos históricos como a queda do muro de Berlim; passado e futuro; existem verdades morais como "Não deves matar nem torturar seres vivos e sencientes pelo mero prazer de torturar"; obras de arte; acontecimentos naturais e campos electromagnéticos. Se nos tivermos decidido pelo naturalismo, tentaremos simplificar esta lista, colocando em alguns casos "existe" entre aspas ou defendendo, em caso extremo, que alguma coisa daquilo que listámos na realidade nem sequer existe. Mas estas manobras já pressupõem uma imagem do mundo a que poderíamos entregar-nos no contexto da ontologia através de um pensamento inicialmente plausível, mas que depois cairia para o modo non sequitur. Este pensamento parte de um argumento muito simples a que eu chamo o motivo ontológico ${ }^{23}$. Este surge esquematicamente da seguinte maneira:

(P1) Existência é uma qualidade: alguma coisa existe, outra coisa não existe.

(P2) Existência não é uma qualidade própria.

(P3) Todas as qualidades são ou qualidades próprias, ou metafísicas ou ontológicas.

(C) Portanto, existência é ou uma qualidade metafísica ou uma qualidade (onto)lógica.

Chama-se primeiramente qualidade própria a uma qualidade que distingue um objecto no mundo de um ou vários outros objectos no mundo. Com isto ela exerce uma das duas funções teoréticas, que se atribui normalmente às qualidades: a função de discriminação. Objectos são diferenciados uns dos outros de tal modo que possuem diferentes qualidades. A outra função teorética de qualidades é a função dos universais, mediante a qual passamos a entender por que alguns objectos são parecidos, isto é, porque

23 Já o chamo assim em M. Gabriel, "Existenz, realistisch gedacht”, p. 178. 
partilham as mesmas qualidades. Mesas castanhas e árvores são parecidas, sendo ambas castanhas, embora sejam objectos diferentes porque as mesas foram fabricadas de algum modo e as árvores não. Ora prima facie é de facto difícil negar que no mundo tudo existe. Efectivamente, no mundo não há nada que não exista. Os objectos que existem não diferem trivialiter uns dos outros, porque existem. Por isso, é um pensamento antigo da ontologia, que "o Ser" seria o género supremo, o conceito mais geral que subsume tudo o que possui quaisquer outras qualidades.

Existência não é, por consequência, uma qualidade própria. Kant expressa isto, dizendo que o Ser não é um predicado real; Hegel diz que Ser e Nada serão uma e a mesma coisa, porque a afirmação de que algo é, é tão geral, que não tem nenhum conteúdo ${ }^{24}$. Frege e Russell retomam $m u$ tatis mutandis os pensamentos desta tradição e chegam à conclusão de que a existência seria em qualquer caso não uma qualidade de primeiro grau, mas uma qualidade de qualidades, isto é, que seria uma qualidade de funções proposicionais, que consiste no facto de serem por vezes verdadeiras. O pensamento de que a existência não será em caso algum uma qualidade como qualquer outra, que esteja no mesmo grau lógico do que a qualidade de ser verde, encontra-se bastante difundido até à filosofia actual. Até aqui, tudo bem.

O próximo passo já conduz a grandes profundidades. Pois se a existência for uma qualquer qualidade, mas não uma qualidade própria, poderíamos refugiar-nos na ideia de que ela seria uma qualidade metafísica. Por qualidade metafísica entendo uma qualidade que coloca algo em relação com o mundo, o conceito fundamental da metafísica. Neste contexto poderia pensar-se que existir significa pertencer ao mundo, estar presente no mundo, ou acontecer-se no mundo ${ }^{25}$. Neste ponto encontramos uma série de ramificações metafísicas. Nomeadamente, podemos reconhecer neste interface ontológico um trilho em direcção ao naturalismo.

Este trilho prevê que o mundo seja identificado com a natureza, e esta finalmente com o universo. Existir significa então ser natural, ou pertencer ao universo. Chamemos a isto o naturalismo ontológico, pois trata-se nesta concepção de uma tese sobre a existência. Entendendo por

${ }_{24} \mathrm{KrV}, \mathrm{A}$ 598/ B 626; Georg Wilhelm Friedrich Hegel, Wissenschaft der Logik, Frankfurt/M.: Suhrkamp, 1986, p. 83.

25 Esta alegação parece pelo menos implicada em depoimentos como o seguinte em Tim Crane, The Objects of Thought, Oxford: Oxford University Press, 2013, p. 95: "My ontological commitments are all those things I take to be in the world. And what I mean by the world is reality, what exists, what has being. Non-existent intentional objects are no part of this. Existent intentional objects are." 
"universo" o campo objectual que investigam nos mais diversos aspectos e nas mais diversas escalas todas as disciplinas específicas da física contemporânea, ser-se-ia não apenas naturalista, mas fisicalista ontológico. Negando-se isso, e permitindo porventura que todas as ciências naturais investiguem com o mesmo direito ontológico a natureza, chegar-se-á a um naturalismo amplo ${ }^{26}$.

Neste ponto é importante reter que a este nível não se pode falar de um reducionismo ontológico. Se existir significa aquilo em que um fisicalista acredita, não será preciso reduzir valores morais ou acontecimentos históricos. Eles então nem sequer existem. Também não é necessário eliminá-los, como tão-pouco é necessário eliminar bruxas, se elas não existem.

Contra o naturalismo ontológico, aliás, já se pronunciou Bertrand Russell, por exemplo no seguinte trecho:

Of course, I know that this belief in the physical world has established a sort of reign of terror. You have got to treat with disrespect whatever does not fit into the physical world. But that is really very unfair to the things that do not fit in. They are just as much there as the things that do. The physical world is a sort of governing aristocracy, which has somehow managed to cause everything else to be treated with disrespect. That sort of attitude is unworthy of a philosopher. We should treat with exactly equal respect the things that do not fit in with the physical world, and images are among them. ${ }^{27}$

Por conseguinte, o reducionismo não é, enquanto tese ontológica (em contraste com uma tese metodológica ou metafísica), opção alguma. Se tanto, ele resulta de suposições adicionais metafísicas a respeito do modo em que os objectos que existem podem ser repartidos por áreas objectuais entre as quais subsistem relações hierárquicas.

A ideia de que existe de facto um grande número de áreas objectuais que, no entanto, podem ser reduzidas metaforicamente a uma camada fundamental da realidade, é na metafísica actual discutida sob a palavra-chave do "fundamentar (grounding)" 28 .

Este debate pressupõe em grande parte, infelizmente, o naturalismo de uso comercial. A procura metafísica pelas relações hierárquicas do acto

26 Cf. neste contexto, por exemplo, Dieter Sturma, "Naturalismus und moralischer Realismus", in: Markus Gabriel, Der Neue Realismus, pp. 396-417.

27 B. Russell, The Philosophy of Logical Atomism, London/New York: Routledge, p. 96.

28 Veja-se sobre o estado do debate a colectânea de Fabrice Correia/Benjamin Schnieder (eds.), Metaphysical Grounding. Understanding the Structure of Reality, Cambridge: Cambridge University Press, 2014. 
de fundamentar ocorre por isso, correntemente, de tal forma que o naturalismo é pressuposto sem fundamento. Cito como exemplo apenas um dos principais representantes do fundamentar, chamemos-lhe o fundador, que é Jonathan Schaffer. Ele acredita que, em última instância, apenas existe o "cosmos" no seu todo ${ }^{29}$. Para tal, no seu ensaio "The Action of the Whole", ele cita três razões consideravelmente fracas: em primeiro lugar, existindo uma disciplina fisicalista designada "cosmologia", deverá por conseguinte existir o cosmos. Em segundo, existia uma série televisiva estadunidense com o nome Cosmos trazida à existência (oxalá isto seja uma piada) por Carl Sagan. Em terceiro, poder-se-ia negar a existência do cosmos apenas enquanto se assumiriam suposições mereológicas despropositadas sobre a relação de totalidades com partes. Apenas o terceiro fundamento pode ser um autêntico fundamento. Infelizmente Schaffer não aprofunda este, de maneira que nem mesmo se sabe o que deveria falar a favor da sua variação naturalista do espinozismo, excepto que ela permite que ele acredite numa hierarquia naturalista, na cosmologia e na série televisiva estadunidense Cosmos.

Seja como for que se tente eliminar estes problemas, subsiste, porém, um problema muito maior e ainda pouco ou nada considerado. Ao ter-se definido "existência" como a circunstância de algo pertencer ao universo ou de esse algo estar presente no mundo, coloca-se imediatamente a questão de saber se o próprio mundo existe. Kant entendeu nitidamente este problema e ocupou-se dele nas antinomias da Dialéctica Transcendental da Crítica da Razão Pura $^{30}$. Kant reconheceu que o mundo não é de forma alguma um objecto no mundo. Como se sabe, ele considerava que todos os objectos no mundo seriam experimentáveis, definindo por isso o mundo, entre outras maneiras, como um "campo de experiências possíveis"31. Para não ser necessário dizer que o mundo não existe, a tradição kantiana diz que o mundo não seria um objecto no mundo, mas uma ideia regulativa. Será, contudo, permitido voltar a perguntar se o mundo existe. Considerá-lo como um horizonte de procura em vez de um objecto no mundo é uma ajuda apenas relativa. Com um olhar mais atento recebe-se

29 Jonathan Schaffer, "On What Grounds What", in: David Chalmers/David Manley/ Ryan Wasserman (eds.), Metametaphysics. New Essays on the Foundations of Ontology, New York: Oxford University Press, 2009, pp. 347-383; Jonathan Schaffer, "Spacetime the One Substance", Philosophical Studies 145 (2009), 131-148; Idem, "Monism. The Priority of the Whole", Philosophical Review 119/1 (2010), 31-76; Idem, The Internal Relatedness of All Things", Mind 119 (2010), 341-376; Idem, "The Action of the Whole", in Proceedings of the Aristotelian Society, Supplementary Volume 87 (2013), pp. 67-87.

30 Cf. Markus Gabriel, Sinn und Existenz, § 2.

$31 \mathrm{KrV}, \mathrm{A} 227 / \mathrm{B} 280 f$. 
de Kant a resposta de que o mundo não pode existir, porque só existem coisas intramundanas, o que, contudo, para Kant, não significa que, com isto, o mundo não existe, mas simplesmente que o conceito de existência não se lhe pode aplicar, o que traz problemas peculiares. Heidegger colocou, a meu ver, este problema no centro dos seus pensamentos, reconhecendo que o mundo apesar de não existir, pelo menos "mundifica" 32 . De facto, esta não é a melhor informação, pelo que será aconselhável largar a tentativa de Heidegger de resolver o problema da existência do mundo. Não deve ser por um acaso infundado que Heidegger se salve na sua forma do poetar e do pensar, porque percebeu, pelo menos, que a suposição de que a existência é presença no mundo é fundamentalmente errónea ${ }^{33}$.

\section{Pluralismo e Realismo}

Permanece ainda a opção de que por "existência" não se trate nem de uma qualidade própria, nem de uma metafísica, mas de uma qualidade (onto)lógica. Considero-a como certo e concebo "existência" como a circunstância de que algo aparece dentro de um campo de sentido. Com o conceito de campo de sentido surgem algumas precisões técnicas que devem ser apresentadas detalhadamente. Para o nosso propósito pode-se formular a tese sobre as peculiaridades independentemente do conceito de campo de sentido. Designamos de pluralismo ontológico a suposição de que existe uma grande quantidade de áreas objectuais. Se algo ocorre numa determinada área objectual, tal reside no facto de as áreas objectuais determinarem as regras da composição que nos podem dar uma explicação sobre aquilo que nelas ocorre ou não. As regras de sequência da série dos números naturais fazem-nos entender porque o número 3 aparece entre $2 \mathrm{e}$ 4; as regras de sequência da mais recente história europeia fazem entender porque existe outra vez uma República Federal da Alemanha reunificada; as regras de sequência da física de partículas porque existem Up Quarks, etc. Eu chamo às regras de sequência "sentidos" e às áreas que ocorrem nos seus enquadramentos "campos", para evitar a associação com uma hipótese extensionalista da teoria dos conjuntos, que se impõe a alguns

\footnotetext{
32 Por exemplo, Heidegger, Wegmarken, Frankfurt a.M.: Klostermann, 1976, p. 164.

33 Para um extenso tratamento, Veja-se Markus Gabriel, "Ist die Kehre ein realistischer Entwurf?", in: David Espinet, Toni Hildebrandt (eds.), Suchen Entwerfen Stiften: Randgänge zu Heideggers Entwurfsdenken, München: Wilhelm Fink Verlag, 2014, pp. 87-106.
} 
quando ouvem a palavra "área objectual" ${ }^{34}$. Quem possui outras preferências, que substitua "campos de sentido" por "esferas", o que porventura corresponde a uma ideia ontológica fundamental em Der logische Aufbau der Welt, de Carnap ${ }^{35}$.

O pluralismo ontológico é então uma posição bem conhecida. Todavia existe uma tendência para secundarizá-lo como um anti-realismo ontológico. Este declara que apenas existe uma pluralidade de áreas, porque nós humanos precisamos de repartir o mundo devido às nossas práticas epistémicas, graças aos nossos mundos simbólicos, graças à nossa divisão científica do trabalho, graças aos nossos jogos de linguagem, etc. Mas com isto pressupõe-se que o mundo é efectivamente uma grande unidade, que apenas aos bocadinhos podemos tornar inteligível para nós. Sem nós, o mundo seria uma unidade. Para muitos representantes de tal opção, isto deixa espaço para um naturalismo metafísico de fundo.

Mas se "existência" significa que algo aparece num campo de sentido, não existe razão para fazer entrar clandestinamente neste nível a tese de uma unidade imaculada da realidade. Com efeito, esta tese nunca deixou de causar reais dificuldades.

Por estas e outras razões, voto tanto por um pluralismo ontológico quanto por um realismo ontológico. Isto significa, neste contexto, que a circunstância de que apenas existem objectos quando eles aparecem em campos de sentidos será representada ou compreendida através de uma bem-sucedida divisão do trabalho científico. Não existe um mundo que precisemos de repartir, mas repartições que deveríamos compreender se não quisermos enganar-nos.

Existe em princípio uma grande quantidade de áreas não compreensíveis e em última instância não simplificáveis nas quais ocorrem objectos que existem por esse motivo. Isto significa certamente que, para existirem, as áreas precisam, por seu lado, de ocorrer em áreas. Bem-entendido, isto não conduz a um problemático regresso ao infinito, já que simplesmente não existe uma única regra a seguir quando se percebe que objectos apenas podem existir em áreas, as quais por sua vez só podem existir em áreas. Porque esta tese não é de natureza metafísica, mas sim ontológica. Não se trata de um privilegiado "lance de olhos, naquilo que é", para retomar mais uma vez uma fórmula heideggeriana, mas de uma tese muito geral que secunda a tese fundamental do realismo neutral.

${ }_{34}$ Markus Gabriel, Sinn und Existenz, §§ 3-4.

35 Cf. por exemplo Rudolf Carnap, Der logische Aufbau der Welt, Hamburg: Felix Meiner Verlag, 1961, p. 223. Cf. também 22s. (§ 23); p. 38s. (§ 29); p. 55s. (§ 41). 
O que é se pretende com esta tese deixa-se retraçar tendo também em conta um diagnóstico clássico da ontologia. Este diagnóstico diz que tudo que o existe não existe meramente, mas possui outras propriedades. $\mathrm{O}$ que existe é sempre alguma coisa que é assim-e-assim. Esta tese completa tradicionalmente o motivo ontológico que mostra que existência não é uma qualidade própria. Eu designo esta tese de que nada existe meramente assim, mas que é sempre também um assim-e-assim, como o descritivismo ontológico. Este pressupõe que tudo que existe se deixa descrever como algo que é um assim-e-assim. A razão para tal não é que nós humanos de certo modo não possamos evitar aplicar conceitos para nos referirmos ao objectos. Pois neste caso seria ainda assim pensável para nós, que os objectos por baixo do limiar de outras determinações, estariam por isso individuados simplesmente porque existem.

Isto significa que o conceito de existência nunca entra em acção de forma pura. Nada subjaz ao conceito de existência, sem subjazer a outros conceitos. Ora, é assim que os outros conceitos, com os quais são expressas as qualidades próprias, se referem a áreas objectuais. O conceito _é um leão refere-se, por exemplo, ao reino dos animais. Se algo é um leão, então é um ser vivo. Se algo é um ser vivo, apresenta um código genético. Leões pertencem a uma área objectual que podemos identificar. Para esse efeito temos a biologia e a zoologia. O conceito _é um sinal, porém, descreve objectos que pertencem à área objectual do trânsito rodoviário, a que correspondem conceitos jurídicos, que tratam de funções normativas de estatuto, mas não de qualidades naturais, que sempre possuem alguma coisa específica, se for o caso do universo ou da natureza. O conceito_é um número primo, por sua vez, descreve a área objectual para que elaboramos a teoria dos números, assim como o conceito_é uma acção moralmente rejeitável ou_é um bom ser humano caracterizam a área em que se entende a ética como disciplina que se ocupa do bem e do mal, isto é, daquilo que é moralmente permitido, ordenado ou proibido.

Existência é, portanto, formulada de modo mais ou menos tradicional como: transcategorialmente geral e, assim, quasi-unívoco. Mas isto não significa que haja uma área objectual universal a que pertence tudo que existe. Foi justamente esta suposição que Gilbert Ryle introduziu em The Concept of Mind como um exemplo padrão de erro categórico.

It is perfectly proper to say, in one logical tone of voice, that there exist minds, and to say, in another logical tone of voice, that there exist bodies. But these expressions do not indicate two different species of existence, for "existence" is not a generic word like "coloured" or "sexed." They in- 
dicate two different senses of "exist," somewhat as "rising" has different senses in "the tide is rising," "hopes are rising" and "the average age of death is rising." A man would be thought to be making a poor joke who said that three things are now rising, namely the tide, hopes and the average age of death. It would be just as good or bad a joke to say that there exist prime numbers and Wednesdays and public opinions and navies; or that there exist both minds and bodies. ${ }^{36}$

O pluralismo ontológico presume que existe afinal uma grande multiplicidade irredutível de áreas objectuais. Bem entendido, daqui não se segue tanto quanto Ryle anseia. Porque o objectivo de Ryle era, a meu ver, a defesa de um anti-reducionismo na filosofia do espírito. Mas, segundo o pluralismo e o realismo ontológico, não estão excluídas reduções ontológicas locais, desde que não se realizem sob o signo de que, em última instância, tudo se poderia reduzir a uma camada fundamental da realidade. Pode-se reduzir, por exemplo, a existência de bruxas a mundos novelísticos ou ao Carnaval de Colónia e expressar-se em seguida de maneira tal que neste sentido não existem bruxas, se bem que elas existam obviamente no Carnaval e no Fausto. A não-existência de bruxas significa então que não existem bruxas num determinado sentido, no sentido em que se pode supô-las na Noruega ou no Blocksberg ${ }^{37}$.

De forma conclusiva pretendo regressar, com a brevidade doravante necessária, à componente epistemológica do realismo ontológico. $\mathrm{Na}$ minha variante, essa componente reside no facto de não podermos ter, relativamente a qualquer área objectual não-vazia, convicções capazes de verdade relativamente aos seus objectos, convicções que pelo menos são verdadeiras ou falsas. A verdade é neste caso tão transcategorialmente universal como a existência. Todas as frases verdadeiras são verdadeiras no mesmo sentido, nomeadamente no sentido minimalista, pois dizem primeiramente o que é o caso, em segundo lugar apresentam uma adequada forma lógica para corresponder à área objectual com que se relacionam, e em terceiro lugar não são apenas verdadeiras porque alguém as julga como verdadeiras. A divergência potencial entre verdade e julgar como verdade, designo-a de "contraste de objectividade" 38 . Um discurso será concebido

36 Gilbert Ryle, The Concept of Mind, London: Penguin, 2000, p. 24. Sobre uma defesa da Quase-Univocidade de Ryle contra as alegações de Quine, cf. o subcapítulo segundo, "Functional Pluralism", do capítulo "Naturalism and the Fate of the M-Worlds" em Huw Price, Naturalism Without Mirrors, Oxford: Oxford University Press, 2011.

37 Cf. neste contexto os pensamentos de Tim Crane em The Objects of Thought.

38 Cf. mais detalhadamente, Markus Gabriel, An den Grenzen der Erkenntnistheorie. Die 
de forma realista exactamente quando, num dado momento, a inserção do predicado de verdade corresponde ao contraste de objectividade.

Se alguém pretender, perante este pano de fundo das minhas exposições, impugnar-lhes a existência de valores morais ou estados mentais, terá de efectuar bastante trabalho conceptual. Não se pode evitar esse trabalho com uma referência ao naturalismo de uso comercial, já que este pouco ou quase nada contribui para a persistência do contraste de objectividade. Por conseguinte, para terminar, concordo com Donald Davidson, que uma vez observou que ele seria um "realist in all departments" 39 . Com efeito, ele considerou que existe uma ligação conceptual entre verdade, factos e objectividade que não pode ser reconduzida nomeadamente ao facto de que, no meio supostamente mental do pensamento, surjam representações mentais que se encontram de forma causal numa relação apropriada com o mundo exterior.

Cada suposição desta espécie que surja no enquadramento do naturalismo de uso comercial tornará de antemão discutível que factos morais no pleno sentido do termo persistam ou que o espírito humano no pleno sentido do termo exista ${ }^{40}$. $\mathrm{O}$ engano, contudo, não reside neste caso nos factos morais ou na existência do espírito humano, mas no facto de que um conglomerado insustentável e bastante infundado de suposições é insuflado para uma imagem do mundo. Isto causou muitos estragos durante um tempo prolongado, sugerindo que nós, como humanos, estamos abertos para verdades morais - que de facto não apenas nos atingem apenas a nós humanos -, enfim, que apenas somos os inventores de valores, que poderemos abolir ou reavaliar. Ora, pode-se tentar reavaliar ou abolir verdades morais - como aquela de que não se deve matar. Chamamos a isto o mal. Além de bem e de mal não nos espera o sobre-humano, mas sim o homem, que acha que não está sujeito a nenhuma norma que ele mesmo não tenha criado. Esta é uma ilusão que o naturalismo de uso comercial não pode em qualquer caso invocar para se justificar, porque também ele é uma ilusão.

notwendige Endlichkeit des objektiven Wissens als Lektion des Skeptizismus, 2. ${ }^{a}$ edição melhorada e ampliada com um pósfácio, Freiburg i. Br./München: Alber, 2014.

39 Donald Davidson, "A Coherence Theory of Truth and Knowledge", in: Ernest LePore (ed.), Truth and Interpretation. Perspectives on the Philosophy of Donald Davidson, Cambridge: Blackwell, 1986, pp. 307-319, aqui: p. 307.

40 Cf. a posição contrária do psicologismo de Crane, com o qual ele compreende que existiria uma "realidade psicológica", que seria "one phenomenon in the world among others" (The Objects of Thought, p. 168). Como Crane deixa claro, não se deveria negar esta posição, senão tornar-se-ia difícil reconhecer de todo que existem frases verídicas acerca de ilusões, objectos fictícios, etc. 
Tradução de

Markus Gabriel. „Für einen nicht-naturalistischen Realismus“, in: M. Marszalek / D. Mersch (eds.): Seien wir realistisch. Neue Realismen und Dokumentarismen in Philosophie und Kunst, Zürich/Berlin: Diaphanes 2016, pp.59-88.

por Dirk Michael Hennrich e Jorge Telles de Menezes

Dirk.Hennrich@gmx.ch

jorgemenezes@iol.pt 